\title{
Spatio-temporal variation analysis of snow cover in China- Pakistan Economic Corridor based on remote sensing technology
}

\author{
Fan $\mathrm{ZHANG}^{1,2,3}$, ZhiHua $\mathrm{ZHANG}^{1,2.3^{*}}$ \\ ${ }^{1}$ Faculty of Geomatics, Lanzhou Jiaotong University; 730070 Lanzhou, China \\ ${ }^{2}$ National-Local Joint Engineering Research Center of Technologies and Applications for National Geographic State Monitoring; 730070 \\ Lanzhou, China \\ ${ }^{3}$ Gansu Provincial Engineering Laboratory for National Geographic State Monitoring; 730070 Lanzhou, China
}

\begin{abstract}
Based on the MODIS10A2 snow product data from 2001 to 2019, the characteristics of annual variation, interannual variation and spatial distribution of snow cover in China Pakistan Economic Corridor from 2001 to 2019 are analyzed by using remote sensing technology. The result shows that: the snow-cover in a year generally starts from the middle of October, and the snow cover area reaches the maximum value in January of the next year, and reaches the minimum value in July. From 2001 to 2019, the snow area of ChinaPakistan Economic Corridor generally showed a decreasing trend. The distribution of snow in the ChinaPakistan Economic Corridor is extremely uneven. The northern area is obviously more than that in the south. The mountainous and plateau areas are with high frequency of snow cover, and the plains are areas with low frequency of snow-cover. Permanent snow-cover is relatively low. Few, mainly concentrated in the Karakoram Mountains, in terms of distribution range, mainly distributed in $4452 \sim 8378 \mathrm{~m}$.
\end{abstract}

\section{Introduction}

The snow, as one of the natural factors of the earth's surface is active, and sensitive to climate change, it reflected the weak by the strong absorption characteristics of important influence on water cycle of the earth's radiation balance, is the indicator of global climate change, $98 \%$ of the world's seasonal snow is located in the northern hemisphere [1-3] China-Pakistan economic corridor area belongs to arid half arid areas, mountain snow melt water is one of the important ways of water supply area rivers.

At present, there have been studies on the temporal and spatial variation of snow-cover in East Asia [4], Central Asia [5], the northern hemisphere [6] and other regions, but there are few studies on the temporal and spatial variation of snow-cover in the China-Pakistan Economic Corridor. Tang Z G [7] use MODIS10A2 snow products such as spatial and temporal distribution of Tianshan snow in 2001-2015 was studied, the results showed that 20012015, Tianshan snow-area is a downward trend overall. Hen W Q [8], such as combination of MODIS data and the DEM elevation data, analyzes the different heights with central Asian snow coverage rate and snow days, the result shows that the snow coverage in different altitude difference is very big, but permanent snow season change of time and space difference is not obvious.

China-Pakistan economic corridor as the region's flagship project all the way, as the use of Pakistan's location advantage, established by the cooperation and mutual benefit, in Kashgar, eventually to Gwadar port trade corridors, on the one hand, it can promote the Pakistani region along the corridor and the economic development of Xinjiang province of China, on the other hand, it has a positive role in improving our homeland [11] and openness with expanded in china-Pakistan economic corridor construction in China in recent years, the snow became one of the main restricting factors, especially the construction of the highway railway, therefore, accurate monitoring of China-Pakistan economic corridor, snow space-time change is of great significance.

\section{Study area}

China-Pakistan economic corridor (Fig. 1) throughout the pamirs and adjacent areas, along the northern mountainous area the highest elevation of $8553 \mathrm{~m}$, the maximum elevation of $3848 \mathrm{~m}$, is the world's highest areas which is affected by the Indian monsoon and westerly winds, China-Pakistan economic corridor to the warm temperate zone continental arid climate in China, Pakistan for more than three-quarters of the study area is subtropical desert grassland climate rainfall less than 200 $\mathrm{mm}$ [12-14].

The data in this paper are MODIS 10a2 snow product data set, which is composed of MODIS / Terra snow cover for 8 days provided by the National Snow and Ice Data Center of the United States. Different pixel values of each image represent different ground features, 25 for no snow, 38 for lakes, 50 for clouds, 200 for snow [15-16]. Using MRT software to splice modis10a2 products, the

*ZhiHua ZHANG: 43447077@qq.com 
coordinate system is transformed into WGS84 coordinates, and the projection is transformed into Albert coordinates. The elevation data is the digital elevation model of strm, and the spatial resolution is $90 \mathrm{M}$. after resampling, it has the same spatial resolution as MODIS data $(500 \mathrm{~m})$.

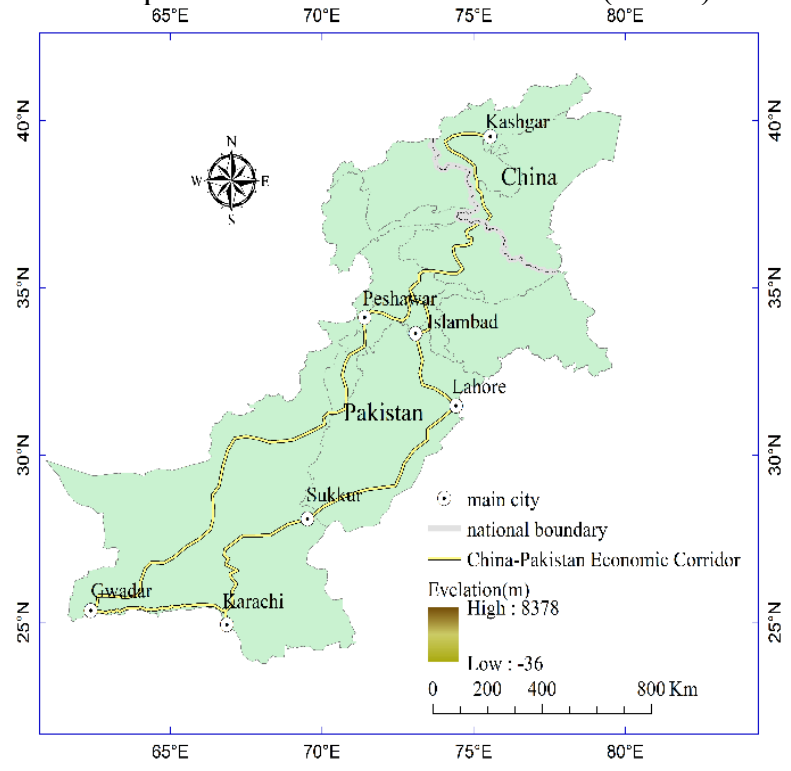

Fig. 1. Study area

\section{Temporal distribution characteristics of snow-cover in China-Pakistan Economic Corridor}

\subsection{Interannual variation of snow-cover}

The maximum area image of snow-cover in a year is obtained by superposition operation of 46 periods of data in a year. The judgment rule of snow pixel is: if there is snow in the image of any 8 days in a year, the pixel is determined as the annual snow pixel. Through the analysis of the annual snow-cover of the China-Pakistan Economic Corridor from 2001 to 2019 (Fig. 2), it can be seen that the snow-cover rate of the China-Pakistan Economic Corridor shows a decreasing trend from 2001 to 2019. From 2001 to 2005 , the snow-cover rate increased obviously. The snow-cover rate fluctuated greatly from 2005 to 2009 . In 2007, the minimum snow- cover rate was $9.44 \%$ in the past 19 years. However, in 2009, the snow-cover rate reached the maximum value of $11.59 \%$, which was the maximum value of 19 years.

Compared with 2001, the annual snow-cover rate in 2009 increased significantly, reaching $1.3 \%$. By comparing and analyzing the annual snow-cover maps of 2001 and 2009, we can see that the change of snow cover area in the north of China Pakistan Economic Corridor is small, while the increase of snow-cover area mainly occurs in the southern mountain area.

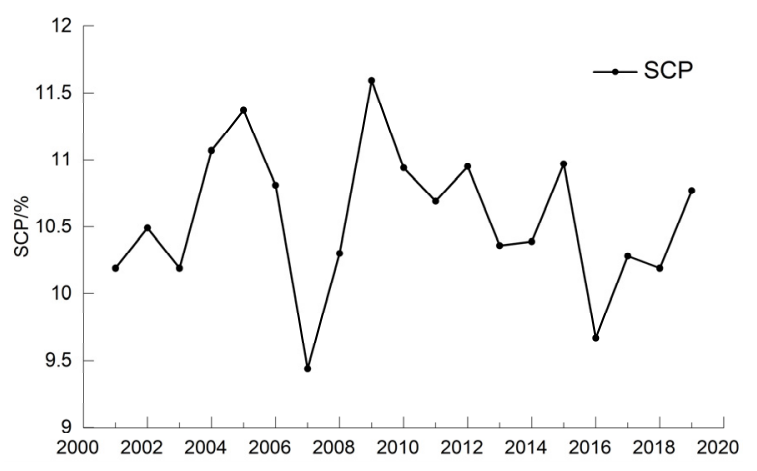

Fig. 2. Interannual snow-cover percent

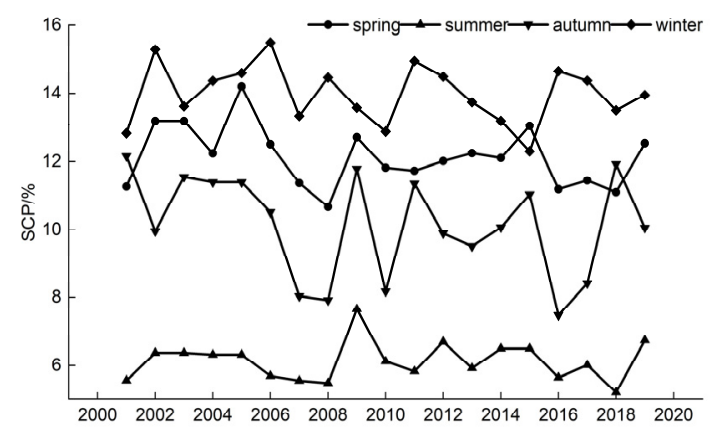

Fig. 3. Seasonal snow-cover percent

\subsection{Seasonal variation of snow-cover}

The snow-cover of China-Pakistan Economic Corridor has obvious seasonal variation. The maximum area of snow-cover in each season is selected as the snow area of that season. The seasons are divided into March, April and may as spring, June, July and August as summer, September, October and November as autumn, December, January and February of the next year as winter. The interannual variation trend of the four periods was obtained (Fig. 3). According to the analysis within the year, the difference of snow-cover rate is obvious in different seasons, summer is far lower than spring, autumn and winter, the highest snow-cover rate is in winter in most years, but the highest snow-cover rate is in spring in 2009. According to the interannual analysis, the snow-cover rate in spring and winter is more than $10 \%$, and the interannual oscillation amplitude of the change of snow-cover rate in autumn is large, and the snow-cover in summer is relatively stable and the change trend is not obvious because it is permanent snow at high altitude.

\subsection{Monthly mean change of snow-cover}

In this paper, the monthly snow image in 19 years is calculated by grid, and the operation rule is: if a pixel shows snow in any scene image in the current month, it is determined as the monthly snow pixel. The snow cover image of China Pakistan Economic Corridor is as shown in figure(fig. 4). For a year, the month with the largest snow-cover rate was January, reaching $14.64 \%$; the month with the smallest snow-cover rate was July, only 5.37\%. Winter is the month with the largest snow coverage rate, with snow coverage rate exceeding $13.5 \%$, followed by March and November, with snow coverage rate of $13.18 \%$ 
and $12.41 \%$. The snow-cover rate in other months is less than $12 \%$. For interannual, the change of snow-cover rate is obvious in the same month, especially in the month with high snow-cover, the interannual fluctuation is greater, and the main interannual fluctuation months are January February and October December.

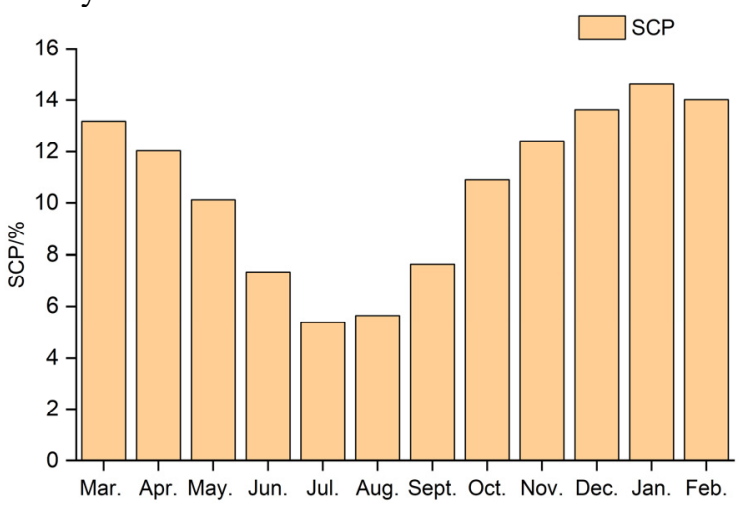

Fig. 4. Monthly snow-cover percent

\section{Spatial distribution characteristics of snow-cover in China-Pakistan Economic Corridor}

\subsection{Altitude distribution of snow-cover}

The altitude span of the China-Pakistan Economic Corridor is large, and the environment of each altitude is obviously different.Therefore,the natural breakpoint classification method is used to re classify the altitude based on the digital elevation data. This method uses statistical formula to determine the natural clustering of attribute values. Its function is to reduce the differences at the same level and increase the differences of different levels, so as to maximize the differences [17-19]. According to the principle of the natural breakpoint method, some continuous but not concentrated data are classified into grades. These grades will set boundaries at the positions where the data values are relatively different, so that the variance within each level is the minimum, and the variance between adjacent levels is the largest.The results relatively eliminate the subjectivity of artificial differentiation. The calculation formula is as follows:

$$
\operatorname{ssd}_{i-j}=\sum_{k=1}^{j}\left(a[k]-M_{i-j}\right)^{2} \quad(1 \leq i \leq j \leq n)
$$

Where, ssd is the boundary value of risk to different degrees; $a$ is an array (array length is $k$ ); $M$ is the average value in each level.

According to the above rules, the annual snow cover ratios of five sub zones from 2001 to 2019 are obtained (Table 1).

Table 1. Zonation based on DEM

\begin{tabular}{ccc}
\hline Zonation & Elevation(m) & Area ratio (\%) \\
\hline 1 & $-36 \sim 707$ & $38.81 \%$ \\
2 & $707 \sim 1772$ & $23.53 \%$ \\
3 & $1772 \sim 3106$ & $11.32 \%$ \\
4 & $3106 \sim 4452$ & $13.85 \%$
\end{tabular}

5

$4452 \sim 8378$

$12.50 \%$

\subsection{Spatial distribution of permanent snow-cover}

There is permanent snow-cover in the study period of China Pakistan Economic Corridor. The image data of June, July and August in summer in the study area were selected, with a total of 12 periods per year and 228 periods in 19 years. Considering the above two factors, several periods of images with snow cover rate less than $5 \%$ are selected, and then the data with cloud pixel number less than $1 \times 10^{4}$ are selected. The intersection of snow pixels is taken to extract the permanent snow, and the spatial distribution map of permanent snow is obtained (Fig. 5).

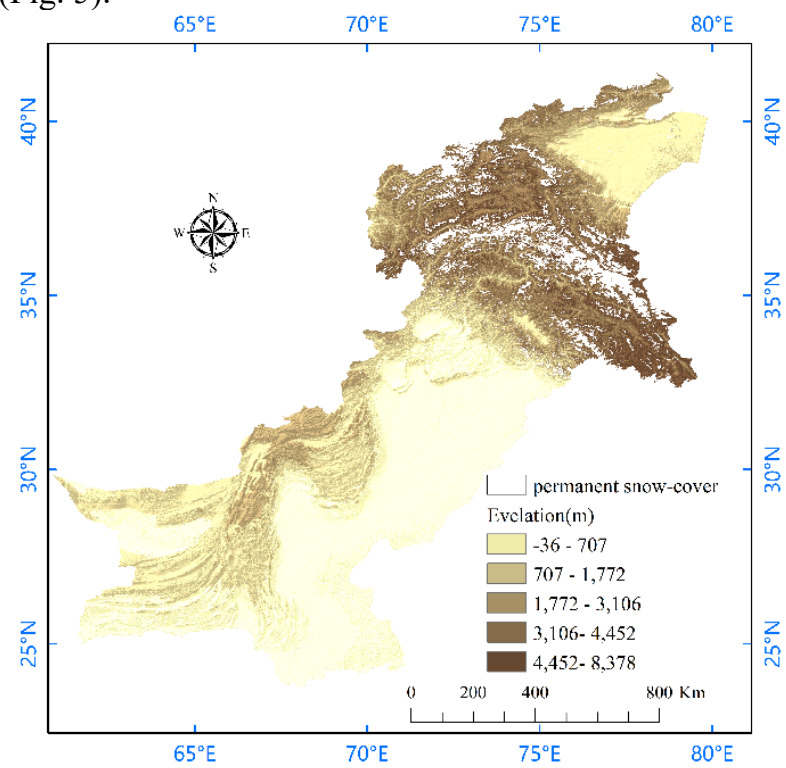

Fig. 5. Permanent snow-cover

The figure shows the spatial distribution of permanent snow-cover in the China Pakistan Economic Corridor. It can be seen from the figure that the permanent snowcover is less distributed in the southern mountains and plains, with a total area of only $150.32 \mathrm{~km}^{2}$, while it is widely distributed in the Himalayas, Hindukush mountains and Karakoram mountains, with an area of $33822 \mathrm{~km}^{2}$.

\subsection{Spatial distribution of snow-cover frequency}

The number of times a pixel is covered by snow is the snow-cover frequency of that pixel. A total of 874 images from 19 years in the study area were analyzed and processed, and the annual snow-cover frequency map of China-Pakistan Economic Corridor from 2001 to 2019 (Fig.6) was synthesized by grid operation. It can be seen from the figure that the high value areas of snow- cover frequency are mainly Pamir Plateau, Karakoram mountains, Himalayas and Xingjiang mountains from north to south Hindukush mountains, the snow frequency in these areas is more than 450 times; the sub high value areas are mainly distributed near the Pamir Plateau, and the snow frequency in the plain areas of the Indus River Basin is low, ranging from 0 to 150 times.

According to the snow-cover ratio of short-term snow- 
cover and long-term snow-cover [23-25], the snow-cover frequency is divided into two categories: short-term snowcover and long-term snow cover. It can be seen from the table that there are great differences in the snow cover of each sub zone. Zone1 is mainly composed of no snowcover and short-term snow-cover, zone 2 is more than zone1 without snow-cover and short-term snow-cover, and the ratio of medium and long-term snow-cover area of sub zone 3,4 and 5 is the largest.



Fig. 6. Snow-cover frequency

\section{Results and discussion}

Based on the analysis of the spatial-temporal situation of snow cover in China Pakistan Economic Corridor from 2001 to 2019, the following conclusions can be drawn:

(1) The snow-cover rate of China-Pakistan Economic Corridor showed a slow decrease trend in the whole 19 years. The snow-cover rate showed a slight upward trend from 2001 to 2005, and fluctuated greatly from 2005 to 2009. In 2007, the snow cover rate was the lowest value in 19 years, but in 2009, the snow-cover rate increased sharply and reached the highest value in 19 years. The snow-cover rate will decrease slowly from 2009 to 2019. The change of snow-cover rate in the northern part of the China -Pakistan Economic Corridor is small, while that in the south is obvious, mainly distributed in mountains and plains.

(2) During the 19 years, the snow accumulated in October every year and reached the maximum value of snowcover rate in January of the next year. The snow began to melt from March to May and reached the minimum value in July. Compared with the proportion of snowcover in four seasons, the maximum snow-cover rate is $15.5 \%$ in winter and $5.2 \%$ in summer.

(3) The snow-cover in summer from 2001 to 2019 is mainly permanent snow-cover, mainly concentrated in the range of $4452-8378 \mathrm{~m}$, and the change trend is not obvious. The snow-cover rate in autumn showed a decreasing trend. The frequency of snow-cover in mountain area was higher (450-873), while that in plain and watershed was lower (0-150).
Table 2. Snow frequency area ratio table of each dividing zone

\begin{tabular}{cccccc}
\hline & Zone1 & Zone2 & Zone3 & Zone4 & Zone5 \\
\hline None & 18.426 & 14.524 & 8.576 & 4.352 & 1.024 \\
Short-term & 88.182 & 54.356 & 38.452 & 22.124 & 11.389 \\
Medium-term & 6.826 & 10.547 & 30.455 & 45.245 & 14.214 \\
$\begin{array}{c}\text { Medium and } \\
\text { long-term }\end{array}$ & 0.000 & 1.128 & 12.154 & 32.741 & 38.147 \\
Long-term & 0.000 & 0.000 & 0.000 & 13.356 & 44.354 \\
\hline
\end{tabular}

\section{Acknowledgments}

The work was supported by the National Key R\&D Program of China (2017YFB0504201, 2017YFB05042 03), the National Natural Science Foundation of China (Project No. 41861059, 41761082, 61862039), and partially supported by LZJTU EP 201806. The authors are grateful to the editors and reviewers more enough for their self-giving works.

\section{References}

1. R.L. Armstrong,M.J. Brodzik, Recent northern hemisphere snow extent: A comparison of data derived from visible and microwave satellite sensors 28(19):3673-3676(2001).

2. S.S Mashtayeva, Dai L, Che T, et al, Spatial and Temporal Variability of Snow Depth Derived from Passive Microwave Remote Sensing Data in Kazakhstan. JMR,30(06):1033-1043(2016).

3. Liu J F,Chen $\mathrm{R}$ S,Song $\mathrm{Y} \mathrm{X}$, Distribution and Variation of Snow Cover in China. Climate Change Research, 8(05):55-62(2012).(in Chinese)

4. Wang Y F,Sun X G, Yang X Q, Role of snow depth in the influence of EL Nino on the summer climate anomalies over East Asia. Chinese Journal of Geophysics. 60(09):3325-3337(2017).(in Chinese)

5. Brown R. D., Robinson D. A., Northern Hemisphere spring snow cover variability and change over 19222010 including an assessment of uncertainty. The Cryosphere. 5(12):219-229. (2011)

6. Zhang N L,Fan X T,Zhu J J, Spatial and temporal distribution characteristics of snow cover in northern hemisphere based on MODIS Snow products. Remote Sensing Information, 27(06):28-34(2012).(in Chinese)

7. Tang $Z$ G,Wang J,Wang $X$, et al, Remote Sensing Study on temporal and spatial variation of snow cover in Tianshan area in recent 15 years. Remote Sensing Technology and Application. 32(03):556563(2017).(in Chinese)

8. Zhong $\mathrm{Z} \mathrm{T}, \mathrm{Li} \mathrm{X}, \mathrm{Xu} \mathrm{X} \mathrm{C}$, et al, Remote sensing analysis of spatial and temporal variation of snow cover in arid region of Central Asia. Chinese Science Bulletin, 63(25):2641-2654(2018).(in Chinese)

9. Wang Y Z,Li H,Liang P, "One belt, one road" construction and China's economic development 
strategy: a case study of the Sino Pakistani Economic Corridor. Qinghai Social Sciences ,2020(03):8388(2020).(in Chinese)

10. Zhao Y X, Yao L K, Wei Y X, et al, Characteristics of platforms along the river of China-Pakistan Economic Corridor and key points of railway route selection. Railway Engineering, 60(07):102-106(2020).(in Chinese)

11. Yin $\mathrm{X}, \mathrm{Hu} \mathrm{X}, \mathrm{Achievements,} \mathrm{challenges} \mathrm{and}$ Countermeasures of infrastructure interconnection project of China-Pakistan Economic Corrido. South Asian Studies Quarterly,2019(03):32-41+5(2019).(in Chinese)

12. Zhang J,Han T,Wang J, Characteristics of platforms along the river of China-Pakistan Economic Corridor and key points of railway route selection. Journal of Glaciology and Geocryology, 2005(05):649654(2005).(in Chinese)

13. Zhou B,Liu B,Zhan L, Study on monitoring of important geographical elements in China-Pakistan Economic Corridor. Geomatics and Spatial Information Technology, 43(06):160164+171(2020).(in Chinese)

14. Yao C,Wang X,Zhao X R, et al, Temporal and spatial variation characteristics of ice lake in China- Pakistan Economic Corridor from 1990 to 2018. Journal of Glaciology and Geocryology ,42(01):33-42(2020).(in Chinese)

15. Lei X C,Song K S,Wang Z M,et al, Accuracy analysis of MODIS and AMSR-E snow cover products in Heilongjiang Basin. Journal of University of Chinese Academy of Sciences, 28(01):43-50(2011).(in Chinese)

16. Wang L F,Zhang S C,Zhang C L, Application of ground based GPS in snow depth inversion in Altay. Desert and Oasis Meteorology,13(01):9398(2019).(in Chinese)

17. Chen X N,Bao A M,Liu P, Accuracy evaluation of mod10al classification in Tianshan Mountains based on multi-scale statistical samples. Remote Sensing for Land \& Resources, (03):80-85(2010).(in Chinese)

18. Zhou S Y,Xiao P F,Feng X Z, et al, Snow recognition in SAR image based on Markov random field model.Journal of Nanjing University(Natural Science),51(05):976-986(2015).(in Chinese)

19. Yuan L,Li C E,Chu S L, Influence of cold season deepening on AMSR-E monitoring snow-cover in Inner Mongolia. Pratacultural Science. (08):2630(2018).(in Chinese) 